\title{
Relationship between Organizational Control and Job Performance of Special Education Teacher in Pakistan
}

\author{
Ibtasam Thakur \\ Assistant Professor Dr., Institute of Education \\ Lahore College for Women University, Lahore \\ Uzma Quraishi \\ Prof. Dr., Director, Institute of Education \\ Lahore College for Women University Lahore \\ Fazal Abbas Rana \\ Public Functionary
}

\begin{abstract}
Over the last decades, Organizational performance has been often studied by different human resource managers. Many studies have suggested how to enhance performance and guide employees. But there is dearth of such researches in the field of special education schools in Pakistan. Keeping in view cultural context of Pakistan this study had examined how organizational control in special education schools was related to teachers' job performance and how effective control could increase job performance. Therefore, purpose of this study was to examine relationship between organizational control and job performance of special education teachers. Using data of 374 special education teachers from 9 districts of the Punjab, researcher found support for research questions. Stratified cluster random sample technique was used to draw the sample. The data was collected through questionnaire developed by the researcher for job performance and organizational control in schools. The results of this study showed that there is positive relationship between job performance and control of organizational culture. Findings of the study showed that if organizational control will be effective, the job performance will also increase and similarly if control in an organization will be weak, job performance of teachers will be decreased. It was concluded that organizational control leave strong impact on job performance of special education teachers. The implications of the results for further directions and research were discussed.
\end{abstract}

Keywords: Job performance, organizational control, Special Education Teachers

\section{Introduction}

Organizational control is a procedure by which an organization directs his subordinates in specific way that lead to fulfill organizational objectives and goals. If organizational control is properly designed and focused, it helps to accomplish organizational strategy and job performance. Organizational control related management practices affect job performance and increase employees' organizational trust as well. (Weibel et al., 2016). Organizational control is strong mechanism which can influence workplace outcomes. (Zhang, Tsui, Song, Li, \& Jia, 2008) Job performance is an important aspect of organizational control. As a result of good and effective organizational control, job performance increases and can be measured properly. Organizational control embroils four steps, first one is to establish standards second one is to measure performance third one is to compare performance against standards and fourth one is to take corrective action as needed. Similarly, job performance is theorized as a multidimensional concept consisting of more than one kind of behaviors that includes, task specific behaviors, non-task specific behaviors, communication, effort, personal discipline, helping out the groups and his or her colleagues, supervisory or leadership component, managerial task (Campbell, 1990).Main 
components of job performance teaching skill, professionalism and job motivation are monitored with the help of organizational control. Although control leads towards better job performance but few organizations like schools may not understand its proper meaning and don't take much interest in control practices while it has been observed that formal practice of control brings fruitful results for an organization. Effect of formal control on performance is much stronger and leads towards accomplishment of organizational goal. In this way, on the one hand, organizational control enhances organization's liability and determination and on the other hand increases job performance. ( Chenhall \& Moers, 2015).

Keeping in view the cultural milieu of Pakistan it is quite obvious that still many special education schools are not that advance as there is dearth of knowledge concerning how control factor can affect job performance of teachers. Consequently, many teachers' job performance outcome is problematic. Ineffective control hampers efficiency and performance of teachers and they lack trust in their organization and leadership. Two reasons have been offered as to why organizational control helps to build trust in their organizations, first, control practices may signal the organization's predictability, fairness, and reliability. In other words, controls may lead to perceived organizational goodwill and as such enable employees to have more trust in their employing organization. Second, control practices may also signal organizational ability and thus may enhance the belief that an organization is capable of delivering its promises to both employees and external stakeholders (Bridoux, Stofberg, \& Den Hartog, 2016). Therefore, it was high time to realize the importance of control in special education schools. Hence, the purpose of this study was to examine relationship between organizational control and job performance of special education teachers in Punjab.

\section{Rationale of the Study}

Organizational control aligns the action of employee with the goal and objectives of an organization. If this control lacks, the whole structure of organization gets weak and job performance decreases. In few Punjab special education schools, practice of control is declined and control has been limited only to the official documents. As a consequence, job performance components: professionalism, teaching skills and job motivation affects and teachers are unable to meet relevant performance standard. Therefore, present study was an effort to identify the gaps between organizational control and job performance.

\section{Research Question}

How organizational control affects job performance of teachers in special schools of Special Education Department, Government of the Punjab?

What is the relationship between job performance components and organizational control?

\section{Objectives of the Study}

To examine the relationship between organizational control and job performance of teachers in special schools of Special Education Department, Government of the Punjab.

To explore the relationship between job performances' components viz. teaching skill, professionalism and job motivation and organizational control.

\section{Method}

\section{Research Design}

The research design applied for this study was descriptive in nature. All the data has been collected and analyzed in numerical form. The researcher's aim was to explore the relationship between organizational control and job performance of special Education teacher. Therefore, the research design was co-relational.

Participants: Participants were obtained from nine (9) randomly selected districts of Punjab. Teachers and heads of special education schools Punjab working in four (4) disabilities were population of this study. Total 374 respondents were selected.

Sample: Cluster stratified random sampling technique was used to collect sample of study.

Instrument: Two questionnaires were used. One was used to measure job performance, three components of job performance, professionalism, job motivation and teaching skill were measured with the help of 30 items questionnaire. Second one was used to measure organizational control consisting of 38 items. These questionnaires were developed by 
the researcher. The reliability of the pilot test for questionnaire of organizational culture was .791. The reliability of the pilot test for questionnaire of job performance was .768.

\section{Results}

\section{Frequency Table}

Table 1: Table of frequencies of distribution of respondents according to their demographics

\begin{tabular}{|c|c|c|c|c|}
\hline Sr. & Variable & & Frequency & Percent \\
\hline \multirow[t]{2}{*}{1} & Gender & Male & 108 & 28.9 \\
\hline & & Female & 266 & 71.1 \\
\hline \multirow[t]{2}{*}{2} & Age & 25 to 40 years & 281 & 75.1 \\
\hline & & 41 to 60 years & 93 & 24.9 \\
\hline \multirow[t]{5}{*}{3} & Education & Matric & 8 & 2.1 \\
\hline & & Intermediate & 8 & 2.1 \\
\hline & & Graduation & 9 & 2.4 \\
\hline & & Masters & 334 & 89.3 \\
\hline & & M.Phil & 15 & 4.0 \\
\hline \multirow[t]{3}{*}{4} & Designation & JEST & 170 & 45.5 \\
\hline & & SST & 135 & 36.1 \\
\hline & & Others & 69 & 18.4 \\
\hline \multirow[t]{4}{*}{5} & Experience & Less than one year & 74 & 19.8 \\
\hline & & 2 to 4 years & 139 & 37.2 \\
\hline & & 5 to 7 years & 84 & 22.5 \\
\hline & & More than 7 years & 77 & 20.6 \\
\hline
\end{tabular}

Table 2: Regression Analysis of control in organizational culture and job performance

\begin{tabular}{lllll}
\hline Variables & Correlation & $\mathrm{B}$ & $\mathrm{r}^{2}$ & Significance \\
\hline Teaching Skill & .217 & .217 & .047 & .112 \\
Professionalism & .118 & .118 & .014 & .393 \\
Job Motivation & .166 & .166 & .028 & .226
\end{tabular}

Table 2 reveals correlation, regression values of organizational culture's variable control and teaching skills of teachers. Table shows that correlation value is .217 , which shows positive correlation between organizational control and teaching skills. This means that teaching skill will decrease with the increase of organizational control and vice versa. Table shows that the value of Beta $(\beta)$ is .217 which also shows the positive relation between teaching skill and organizational control and there is no statistical significant difference as the significance value is .112. It means there is no significant difference between respondents opinion. While on the other hand $\mathrm{R}$ - square $\left(\mathrm{r}^{2}\right)$ value is .047 , which means it can be said with $53 \%$ confidence that if control will increase the teaching skill will decrease.

Table 2 reveals correlation, and regression values of organizational culture's variable control and professionalism of teachers. Table shows that correlation value is .118 , which shows that there is positive correlation between organizational 
control and professionalism of teachers. This means that professionalism of teachers will decrease with the increase of control in organization and vice versa. Table shows that the value of Beta $(\beta)$ is . 118 which also shows the positive relation between professionalism of teachers and organizational control and there is no statistical significant difference as the significance value is .393. It means there is no significant difference between respondents' opinion. While on the other hand $\mathrm{R}$ - square $\left(\mathrm{r}^{2}\right)$ value is .014 , which means it can be said with $86 \%$ confidence that if organizational control will increase the professionalism of teachers will decrease.

Table 2 reveals correlation, and regression values of organizational culture's variable control and job motivation of teachers. Table shows that correlation value is .166, which shows that there is positive but very weak correlation between organizational control and job motivation of the teachers. This means that job motivation of teachers will increase with the increase of organizational control. Table shows that the value of Beta $(\beta)$ is .166 which also shows the positive but very weak relation between job motivation of teachers and organizational control and that is no statistical significant difference as the significance value is .226. It means there is no significant difference between respondents' opinion. While on the other hand $\mathrm{R}$ - square $\left(\mathrm{r}^{2}\right)$ value is .028 , which means it can be said with $72 \%$ confidence that if control will increase, the job motivation of teachers will also increase.

Overall this table reveals that there is positive relationship between job performance and control of organizational culture. If control will be effective, the job performance will increase and similarly if control in an organization will not work, job performance of teachers will decrease.

\section{Findings}

Correlation value which is .217 , shows that there is positive correlation between organizational control and teaching skills. This means that teaching skill will decrease with the increase of organizational control. Correlation value which is .118, shows that there is positive correlation between organizational control and professionalism of teachers. This means that professionalism of teachers will decrease with the increase of control in organization. Correlation value which is .166, shows that there is positive but very weak correlation between organizational control and job motivation of the teachers. This means that job motivation of teachers will increase with the increase of organizational control.

\section{Conclusion}

Effective control is essential in schools; if it is strong then quality of job performance will be high. Similarly, if control in an organization will not work effectively then standard of job performance will decrease among teachers. Result of this study suggests organizational control creates integrity in structure and function of an organization and job performance may be enhanced by implementing organizational control. Therefore, there is need to focus on organizational control in special education schools and this research may lay foundation for further research in this field.

\section{Recommendations}

In order to enforce effective control a formal mechanism in schools may be introduced to meet goals and objectives of an organization. It may help to raise job performance standard of teachers. To enhance three components of job performance, professionalism, job motivation and teaching skills, it should be aligned with better organizational control. Organizational control plays a vital role in shaping the organizational culture and job performance. Heads of institute of special education department should focus on organizational control strategies, which could reduce emotional exhaustion and may increase job performance among special education teachers. 


\section{References}

[1] Bridoux, F., Stofberg, N., Den Hartog, D. (2016). Stakeholders' responses to CSR tradeoffs: When otherorientation and trust trump material self-interest. Frontiers in Psychology, 6. doi:10.3389/fpsyg.2015.01992.

[2] Chenhall, R. H., Moers, F. (2015). The role of innovation in the evolution of management accounting and its integration into management control. Accounting, Organizations and Society, 47, 1-13. Google Scholar, Crossref

[3] Campbell, J. P. (1990). Modeling the performance prediction problem in industrial and organizational psychology. In M. D. Dunnette \& L. M. Hough (Eds.), Handbook of Industrial and Organizational Psychology (pp. 687-732). Palo Alto, CA: Consulting Psychologists Press, Inc.

[4] Weibel, A., Den Hartog, D. N., Gillespie, N., Searle, R., Six, F., Skinner, D. (2016). How do controls impact employee trust in the employer? Human Resource Management, 55, 437-462. Google Scholar, Crossref

[5] Zhang, A. Y., Tsui, A. S., Song, L. J., Li, C., Jia, L. (2008). How do I trust thee? The employee-organization relationship, supervisory support, and middle manager trust in the organization. Human Resource Management, 47, 111-132. Google Scholar, Crossref, ISI 